\title{
Community-acquired Legionnaires' Disease in a Newly Constructed Apartment Building
}

\author{
Sukhyun Ryu ${ }^{1,2}$, Kyungho Yang ${ }^{1}$, Byung Chul Chun ${ }^{2,3}$ \\ ${ }^{1}$ Division of Infectious Disease Control, Gyeonggi Provincial Government, Suwon; ${ }^{2}$ Department of Epidemiology and Medical Informatics, School of \\ Public Health, Korea University, Seoul; ${ }^{3}$ Department of Preventive Medicine, Korea University College of Medicine, Seoul, Korea
}

Objectives: Legionnaires' disease (LD) is a severe type of pneumonia caused by inhalation of aerosols contaminated with Legionella. On September 22, 2016, a single case of LD was reported from a newly built apartment building in Gyeonggi province. This article describes an epidemiologic investigation of LD and identification of the possible source of infection.

Methods: To identify the source of LD, we interviewed the patient's husband using a questionnaire based on the Legionella management guidelines from the Korea Centers for Disease Control and Prevention. Water samples from the site were collected and analyzed. An epidemiological investigation of the residents and visitors in the apartment building was conducted for 14 days before the index patient's symptoms first appeared to 14 days after the implementation of environmental control measures.

Results: Legionella pneumophila serogroup 1 was isolated from the heated-water samples from the patient's residence and the basement of the apartment complex. Thirty-two suspected cases were reported from the apartment building during the surveillance period, yet all were confirmed negative based on urinary antigen tests.

Conclusions: The likely source of infection was the building's potable water, particularly heated water. Further study of effective monitoring systems in heated potable water should be considered.

Key words: Legionella, Potable-water system, Infection, Disease outbreaks, Korea

\section{INTRODUCTION}

Legionella pneumophilia (LP) causes from 1 to $4 \%$ of cases of community-acquired pneumonia (CAP) [1,2]. Pathogenic Legionellaceae are fastidious gram-negative bacteria that thrive in warm and stagnant water, particularly when scale, sediments, and biofilms are present and when there is not an adequate quantity of biocides [3].

Received: April 25, 2017 Accepted: June 12, 2017

Corresponding author: Kyungho Yang, MD

11 Hyowon-ro, Paldal-gu, Suwon 16444, Korea

Tel: +82-31-8008-5428, Fax: +82-31-8008-4179

E-mail: ykh110124@gmail.com

This is an Open Access article distributed under the terms of the Creative Commons Attribution Non-Commercial License (http://creativecommons.org/licenses/by$\mathrm{nc} / 4.0 / /$ which permits unrestricted non-commercial use, distribution, and reproduction in any medium, provided the original work is properly cited.
Infection by Legionella in humans results from the inhalation or aspiration of aerosols contaminated with the bacteria, causing illnesses such as Pontiac fever and Legionnaires' disease (LD). Previous studies have shown that the Legionella is often associated with natural environments such as hot springs and soil, as well as with human-made water systems, such as watersupply facilities [4]. Previously reported routes of exposure have been linked to air-conditioning cooling towers, whirlpool spas, and tap-water-distribution systems. On September 22, 2016, the provincial epidemiologist from the Division of Infectious Disease Control in Gyeonggi Provincial Government was notified of a case of LD. A 58-year-old woman with diabetes presented to the emergency room with a fever, cough, and shortness of breath. She was diagnosed with CAP, based on clinical and radiologic findings. As aggravating her respiratory symptoms, she was transferred to the intensive care unit for 
mechanical ventilation. A urinary antigen test (Alere Binax NOW, Alere Inc., Waltham, MA, USA) for detecting Legionella, an atypical pneumonia serology test including Mycoplasma, and a viral polymerase chain reaction screen and culture test with blood and sputum for respiratory pathogens were conducted during her admission. The urinary antigen test was positive, and the other laboratory tests screening for respiratory pathogens were negative.

On September 30, 2016, an environmental investigation was conducted to identify the source of infection and recommend control measures to prevent additional cases.

The purpose of this study is to describe the procedures used by the epidemiologic and environmental investigations of this case and to recommend control measures to prevent future outbreaks of LD.

\section{METHODS}

\section{Case Investigation}

To identify the source of LD, we interviewed the patient's husband, who is a cohabitant, using the questionnaire based on the Legionella management guidelines from the Korea Centers for Disease Control and Prevention [5]. The questionnaire collected information regarding recent travel history to determine if the patient had been exposed to aerosols from sources such as hot springs or spas in the 14 days before her symptoms began. The information gathered was then used to make a hypothesis regarding potential sources of infection.

\section{Environmental Investigation}

The environmental investigation was mainly focused on the domestic potable-water system because the patient had spent most of her time in her apartment, had taken a hot shower every day, and had not traveled to a source of aerosols, such as a hot spring or spa.

The patient's apartment building was built in November 2015 and is a 20-story building with 148 apartment units. The apartment complex uses the municipal water supply and has its own water-heating system to provide hot water to the individual apartment units.

In total, 9 water samples were collected and their temperature and residual chlorine levels measured. Water samples were collected from the water-storage tank of the apartment complex, upper and lower sites in the hot-water circulation loop, the tap for hot and cold water in the basement of the apartment complex, and the tap for hot and cold water in both the patient's bathroom and kitchen (Table 1).

Water samples were collected in 1-L polypropylene bottles. The buffered charcoal yeast extract agar was used as a standard medium to detect the growth of Legionella colonies [5].

\section{Epidemiological Investigation}

We notified all inhabitants in the apartment complex with the result of the environmental investigation by sending them an official notice and making a public announcement. The day after the public announcement, control measures were implemented, such as superheating the water-heating system and

Table 1. Temperature, residual chlorine, and Legionella growth ${ }^{1}$ from collected water samples

\begin{tabular}{|c|c|c|c|}
\hline Collection site & Temperature $\left({ }^{\circ} \mathrm{C}\right)$ & Residual chlorine (ppm) & Legionella growth (CFU) \\
\hline Water-storage tank & 20 & 0.43 & 0 \\
\hline \multicolumn{4}{|c|}{ Hot-water circulation loop } \\
\hline Upper site & 49 & 0.07 & 47200 \\
\hline Lower site & 43 & 0.16 & 29400 \\
\hline \multicolumn{4}{|l|}{ Apartment basement } \\
\hline Hot water & 43 & 0.00 & 32400 \\
\hline Cold water & 20 & 0.09 & 0 \\
\hline \multicolumn{4}{|l|}{ Bathroom } \\
\hline Hot water & 43 & 0.04 & 72000 \\
\hline Cold water & 20 & 0.09 & 0 \\
\hline \multicolumn{4}{|l|}{ Kitchen } \\
\hline Hot water & 43 & 0.28 & 56000 \\
\hline Cold water & 20 & 0.09 & 0 \\
\hline
\end{tabular}

ppm, parts per million; CFU, colony forming unit.

${ }^{1}$ Legionella growth was analyzed at the provincial public-health laboratory. 
hyperchlorination of the water in the storage tank. At this point, we also initiated the epidemiological investigation for all of the residents and visitors in the apartment building. Suspected cases were defined as individuals experiencing fever, myalgia, cough, or a mild illness with or without pneumonia from 14 days before the index patient's symptoms first appeared to 14 days after the implementation of the environmental control measures [5]. For these cases, we collected urine samples and performed a urinary antigen test (Alere BinaxNOW). Confirmed cases were defined as those (1) with clinical or radiological evidence of pneumonia and the presence of LP in cultures or respiratory specimens as determined by microbiological analysis; (2) with a fourfold rise in serum antibody levels against LP serogroup 1; (3) with LP antigen detected in their urine; or (4) who tested positive for LP based on immunofluorescence assays over the same time period defined for suspected cases [6].

\section{RESULTS}

\section{Case Findings}

We identified 32 suspected LD cases. All of them reportedly experienced fatigue without fever or any respiratory symptoms. The Legionella urinary antigen tests were negative in all suspected cases. Furthermore, there were no reported laboratory-confirmed cases.

\section{Results of the Environmental Investigation}

The environmental investigation assessed the complex water-distribution system in the index patient's apartment building. Water temperature and residual chlorine levels were measured and ranged from 20 to $49^{\circ} \mathrm{C}$ and from 0.00 to 0.43 parts per million, respectively.

LP was not isolated from the water tank. In the index patient's residence, however, LP serogroup 1 was isolated, specifically from the hot-water circulation loop and the hot-water taps (Table 1).

\section{DISCUSSION}

If an outbreak of $L D$ developed, it could begin with a report of a single infected patient [7]. Thus, determining possible sources of infection is critical for identifying and preventing further cases. This study describes the investigation of a single case of Legionella infection in a newly built apartment build- ing and the result of a surveillance program. LP serogroup 1 was detected from heated potable water in the index patient's residence and in the basement of the apartment building, which is outside the patient's residence but is linked to it and all the other apartment units. Thirty-two people in the apartment complex reported that they had experienced mild myalgia during the period considered during the epidemiologic investigation. However, all of these individuals were confirmed as not being infected by the laboratory tests. When the environmental control measures were implemented, including hyperchlorination of the water in the storage tank, residents were instructed to open their tap, discarding the water, and then drink water boiled for a day of treatment of any remaining water with the bacteria. After the control measures were implemented, there was no evidence of Legionella at any of the sites where it previously had been detected.

These epidemiological and environmental investigations suggested that the water-heating system was likely the source of transmission. The host factor of having diabetes mellitus also predisposed the patient to infection with LD [6]. Since 2000, LD has been designated as a reportable infectious disease in Korea, and the incidence was between 0.04 and 0.09 per 100000 persons from 2010 to 2015 [5]. However, the number of annual reported cases is rising, with an incidence of 0.25 per 100000 persons in 2016 [8]. The reason for this rapid increase is unclear, although increased testing for differential diagnosis of pneumonia, increased reporting, and the growth of the old-age population are likely contributing factors [9].

To reduce the incidence of $L D$, the World Health Organization and the US Center for Disease Control and Prevention have recommended the development of a regular monitoring program for water systems where Legionella is most likely to thrive $[10,11]$. It is well established that the heating process can degrade the level of disinfectant [11]. Furthermore, these guidelines and studies support our finding that inadequate disinfectant is one of significant environmental risk factors for Legionella contamination $[12,13]$. Thus, this indicates monitoring residual chlorine, particularly in heated potable water, is critical for public facilities, even for newly constructed buildings.

This investigation has several limitations. First, the urinary antigen may persist for prolonged periods of time (up to almost 1 year) in the urine of a patient who has been infected [14], meaning that the index patient could have been infected previously. However, the index patient had no prior medical history of respiratory symptoms, therefore a prior infection is 
unlikely. Second, we did not conduct a molecular study to identify the serogroup of Legionella from the index patient. However, LP serogroup 1 is responsible for 70 to $90 \%$ of human infection, and the Legionella urinary antigen test reliably detects LP serogroup 1 [4]. Third, we only collected potable water samples from a few sites outside the residence. Fourth, the $\mathrm{pH}$ level of the water samples was not measured.

In conclusion, this is the first study of LD infection in a newly constructed apartment building in Korea. Our results suggest that the likely source of infection was the building's potable water, particularly heated water. In order to avoid LD outbreaks in the future, we believe additional studies of effective monitoring systems in heated potable water are necessary.

\section{ACKNOWLEDGEMENTS}

The authors would like to thank the public-health officers from Pyeongteak City Department of Health for their assistance with this investigation and the microbiologists from the provincial public-health laboratory for promptly providing us with the results of the laboratory tests.

\section{CONFLICT OF INTEREST}

The authors have no conflicts of interest associated with the material presented in this paper.

\section{ORCID}

Sukhyun Ryu https://orcid.org/0000-0002-8915-8167

Kyungho Yang https://orcid.org/0000-0001-6647-7790

Byung Chul Chun https://orcid.org/0000-0001-6576-8916

\section{REFERENCES}

1. Yu VL, Stout JE. Community-acquired legionnaires disease: implications for underdiagnosis and laboratory testing. Clin Infect Dis 2008;46(9):1365-1367.

2. Miyashita N, Matsushima T, Oka M. The JRS guidelines for the management of community-acquired pneumonia in adults: an update and new recommendations. Intern Med 2006;45 (7):419-428.

3. Quinn C, Demirjian A, Watkins LF, Tomczyk S, Lucas C, Brown E, et al. Legionnaires' disease outbreak at a long-term care facility caused by a cooling tower using an automated disinfection
system--Ohio, 2013. J Environ Health 2015;78(5):8-13.

4. Thomas S, Hassan I, Barker J, Ashworth A, Barnes A, Feddy L, et al. Two cases of community acquired Legionella pneumophila non-serogroup 1 in patients undergoing extra corporeal membrane oxygenation for severe respiratory failure. JMM Case Rep 2014. doi: https://doi.org/10.1099/jmmcr.0. 000002.

5. Korea Centers for Disease Control and Prevention. Guideline of Legionnaires' disease. Cheongju: Korea Centers for Disease Control and Prevention; 2016, p. 20, 31, 40, 70-73 (Korean).

6. World Health Organization. Legionella and the prevention of legionellosis; 2007 [cited 2017 Jun 15]. Available from: http:// www.who.int/water_sanitation_health/emerging/legionella. pdf.

7. Lee JV, Joseph C; PHLS Atypical Pneumonia Working Group. Guidelines for investigating single cases of Legionnaires' disease. Commun Dis Public Health 2002;5(2):157-162.

8. Korea Centers for Disease Control and Prevention. Infectious disease statistics systems [cited 2017 Jun 15]. Available from: http://is.cdc.go.kr (Korean).

9. Ameneshoa W, Lee JH, Carlo JT. Community-acquired Legionnaires' disease in Dallas county, Texas. J Environ Health 2016; 78(8):E1-E6.

10. American Institute of Architects. Guidelines for design and construction of hospital and health care facilities; 2001 [cited 2017 Jun 15]. Available from: https://www.fgiguidelines.org/ wp-content/uploads/2015/08/2001guidelines.pdf.

11. Demirjian A, Lucas CE, Garrison LE, Kozak-Muiznieks NA, States $S$, Brown EW, et al. The importance of clinical surveillance in detecting legionnaires' disease outbreaks: a large outbreak in a hospital with a Legionella disinfection system-Pennsylvania, 2011-2012. Clin Infect Dis 2015;60(11):1596-1602.

12. Centers for Disease Controls and Prevention. Developing a water management program to reduce Legionella growth and spread in buildings: a practical guide to implementing industry standards; 2017 [cited 2017 Jun 15]. Available from: https://www.cdc.gov/legionella/maintenance/wmp-toolkit. html.

13. Francois Watkins LK, Toews KE, Harris AM, Davidson S, AyersMillsap S, Lucas CE, et al. Lessons from an outbreak of Legionnaires' disease on a hematology-oncology unit. Infect Control Hosp Epidemiol 2017;38(3):306-313.

14. Kohler RB, Winn WC Jr, Wheat LJ. Onset and duration of urinary antigen excretion in Legionnaires disease. J Clin Microbiol 1984;20(4):605-607. 